\title{
DIFERENCIAÇÃO DE GENÓTIPOS DE TRIGO QUANTO À TOLERÂNCIA À DEFICIÊNCIA DE FÓSFORO, EM SOLUÇÃO HIDROPÔNICA ${ }^{(1)}$
}

\author{
Adriano Alves da Silva ${ }^{(2)}$, Ingrid Arns ${ }^{(3)}$, Christina Venzke Simões de Lima ${ }^{(4)}$, \\ Adriano de Bernardi Schneider ${ }^{(5)}$ \& Carla Andrea Delatorre ${ }^{(6)}$
}

\section{RESUMO}

O P é um dos elementos mais críticos para a produção agrícola, pois, além de sua grande importância para as plantas, sua disponibilidade é cada vez mais limitada em virtude da progressiva escassez das suas jazidas. A diferenciação de genótipos quanto à tolerância à deficiência de $\mathrm{P}$ permite investigar os mecanismos atuantes e o desenvolvimento de genótipos que combinem diferentes mecanismos, aumentando o nível de tolerância. O objetivo deste trabalho foi diferenciar, em solução hidropônica, genótipos de trigo contrastantes quanto à tolerância à deficiência de $\mathrm{P}$. Foram realizados três estudos. No primeiro, avaliou-se o efeito da retirada do endosperma na resposta de plântulas à limitação de $P$. No segundo estudo, foram avaliadas características de plântulas, submetidas a diferentes doses de $\mathbf{P}$, dos cultivares Anahuac, sensível, e Toropi, tolerante. No terceiro estudo, foram avaliadas cinco linhagens recombinantes do cruzamento entre Toropi e Anahuac. A remoção do endosperma da semente é necessária para diferenciar genótipos quanto à tolerância à deficiência de $\mathrm{P}$ em solução nutritiva, aos 10 dias da germinação. A diferenciação de genótipos é feita pelo cálculo da razão entre a concentração de fosfato livre $(\mathrm{Pi})$ na parte aérea obtida nas doses de 10 e de $1.000 \mu \mathrm{mol} \mathrm{L}^{-1}$ de $\mathrm{P}$, ficando, nos genótipos tolerantes, essa razão próxima de $1,0 \mathrm{e}$, nos sensíveis, próxima de 0,5 . As quantidades de Pi na parte aérea ou total na plântula também podem ser utilizadas. O cultivar Toropi e os genótipos NYW 865016, NYW 865-081 e NYW 865-086 são mais tolerantes à deficiência de $P$ em solução

\footnotetext{
(1) Parte de Tese de Mestrado do primeiro autor, apresentada ao Departamento de Plantas de Lavoura, Universidade Federal do Rio Grande do Sul - UFRGS. Desenvolvido com apoio financeiro da FAPERGS (Proc. $\mathrm{n}^{\circ}$ 05.2171.6). Recebido para publicação em junho de 2007 e aprovado em fevereiro de 2008.

${ }^{(2)}$ Doutorando do Programa de Fitotecnia, Universidade Federal do Rio Grande do Sul - UFRGS. Caixa Postal 15100, CEP 90001970 Porto Alegre (RS). Bolsista do CNPq. E-mail: agroadriano@terra.com.br

(3) Aluna do Curso de Agronomia, UFRGS. Bolsista de iniciação científica do CNPq. E-mail: hollie_bani@hotmail.com

(4) Mestranda do Programa de Ciência do Solo, UFRGS. E-mail: chris.solos@yahoo.com.br

(5) Aluno do Curso de Ciências Biológicas da Pontifícia Universidade Católica do Rio Grande do Sul - PUCRS. Bolsista de iniciação científica da FAPERGS. E-mail: abschneider_@hotmail.com

(6) Professora Adjunta do Departamento de Plantas de Lavoura, UFRGS. E-mail: cadtorre@ufrgs.br
} 
nutritiva, quando comparados aos do cultivar Anahuac e aos genótipos NYW 865084 e NYW 865-073. A tolerância de Toropi nas condições avaliadas não se deve ao volume do sistema radicular, mas possivelmente a fatores relacionados com o transporte e uso de $\mathrm{Pi}$ internamente.

Termos de indexação: Triticum aestivum, fosfato, estádios iniciais.

\title{
SUMMARY: DIFFERENTIATION IN HYDROPONIC SOLUTION OF WHEAT GENOTYPES INRELATION TO TOLERANCE TO PHOSPHORUS STARVATION
}

\begin{abstract}
Phosphorus ( $P$ ) is one of the most critical elements for agriculture, not only by the high P requirement for adequate crop growth and development, but also by the gradual scarcity of its natural sources. The differentiation among genotypes is required for further mechanism investigation, and to combine different mechanisms at the same individual which might allow superior tolerance. This work aimed to differentiate, in hydroponic solution, wheat genotypes with contrasting $P$ deficiency tolerance. Three studies were carried out. In the first one, the effect of endosperm removal on wheat seedling $P$ response was evaluated. In the second one, seedlings from two wheat cultivars contrasting in the response to $P$ starvation, Anahuac (sensitive) and Toropi (tolerant) were evaluated at different $P$ availabilities. In the third study, five recombinant inbred lines were evaluated in hydroponic solution. The wheat endosperm contains enough $P$ to mask the seedling $P$ response. The endosperm removal allows evaluation of $P$ tolerance in 10 days-old seedlings. The ratios between shoot free phosphate (Pi) concentration at 10 and $1.000 \mu \mathrm{mol} \mathrm{L} L^{-1} P$ doses can identify the tolerant genotypes. Tolerant genotypes have a ratio around 1.0 and sensitive ones have around 0.5 ratio. The total amount of Pi in the shoot or in the whole plant can also be used. Toropi and the inbred lines NYW 865-016, NYW 865-081 and NYW 865-086 are more tolerant than Anahuac and the inbred lines NYW 865-034 e NYW 865-073. Toropi tolerance, at the conditions used in this work, is not due to root system volume but might be related to $P$ transport and $P$ internal use.
\end{abstract}

Index terms: Triticum aestivum, phosphate, initial growth.

\section{INTRODUÇÃO}

O trigo (Triticum aestivum) é uma cultura importante para o Estado do Rio Grande do Sul, tanto como fonte de renda para os agricultores como para o estabelecimento e manutenção do sistema de semeadura direta, fornecendo palha, além de outros benefícios resultantes da sucessão a culturas como a da soja.

Para obter elevados rendimentos, há necessidade de, entre outros fatores, disponibilizar nutrientes de forma e em quantidade adequadas. Entre os macronutrientes que mais interferem no rendimento das culturas está o P. O estudo do potencial genéticoadaptativo de cultivares à limitação de $\mathrm{P}$ é importante na América do Sul, onde 80 \% dos solos sob condições naturais apresentam teores desse nutriente considerados baixos para o desenvolvimento da maioria das culturas (Sanchez \& Salinas, 1981; Novais \& Barros, 1997), além de elevada capacidade de fixação desse nutriente (Leal \& Velloso, 1973; Gonçalves et al., 1997), resultando em baixa eficiência da adubação fosfatada (Goedert, 1998). O P é um dos nutrientes mais críticos para a produção agrícola, por sua relativa escassez edáfica, elevada retenção por parte da matriz do solo, falta de reposição natural e progressiva escassez das fontes naturais, afetando o crescimento e o rendimento das culturas.

As plantas absorvem $\mathrm{P}$ na forma de $\mathrm{H}_{2} \mathrm{PO}_{4}{ }^{-}$. O P, na forma em que se encontra presente na solução dos solos, é pouco ativo em virtude da reação com outros minerais. Em sistemas intensivos de produção, são muito utilizadas fontes inorgânicas e orgânicas de P; todavia, parte deste nutriente não é recuperada do solo, visto que cerca de $80 \%$ do $\mathrm{P}$ torna-se adsorvido ou complexado junto com resíduos de metais pesados. Os adubos fosfatados utilizados para suprir a deficiência natural de $\mathrm{P}$ dos solos são originários de reservas não-renováveis. Por esse motivo, busca-se melhorar o seu aproveitamento pelas plantas para obter rendimentos similares com menor aporte de $\mathrm{P}$.

A habilidade de uma planta produzir, sob baixa disponibilidade de $\mathrm{P}$, quantidade de matéria seca similar à obtida sob alta disponibilidade é chamada 
de tolerância à deficiência de P. A utilização de cultivares tolerantes é uma alternativa para a redução do custo de produção e da contaminação do ambiente e para a maximização da produtividade das culturas sob condições de estresse. Para isso, é fundamental o conhecimento dos processos relativos à tolerância, os quais podem estar relacionados com os sistemas regulatórios de aquisição e uso de P. Para que esse entendimento seja alcançado, é necessária a diferenciação de genótipos quanto à sua tolerância à deficiência de $\mathrm{P}$, para que, a partir desses, sejam investigados os mecanismos envolvidos nesse processo adaptativo, permitindo, no futuro, identificar os genes envolvidos e desenvolver estratégias para obtenção de genótipos mais tolerantes à deficiência de $\mathrm{P}$ e, assim, manter a produtividade das culturas mesmo em condições limitantes desse nutriente.

A tolerância à deficiência de $\mathrm{P}$ pode ser devida à quantidade desse nutriente necessária para as reações bioquímicas da planta, à redistribuição para os pontos de crescimento, à mobilização do $\mathrm{P}$ armazenado nos vacúolos (Gerloff \& Gabelman, 1983), ao tamanho do sistema radicular, à capacidade de aquisição ou à taxa de absorção de $\mathrm{P}$ por unidade de comprimento radicular (Fernandes, 2001). Do ponto de vista fisiológico, a tolerância deve-se à eficiência nutricional e refere-se à habilidade do genótipo em absorver o nutriente do solo, distribuí-lo e utilizá-lo internamente na produção de matéria seca (Goddard \& Hollis, 1984). Essas habilidades são definidas por fatores morfológicos e fisiológicos e pela demanda nutricional da planta (Marschner, 1995).

Em termos práticos, quando o suprimento de $\mathrm{P}$ do solo é baixo, genótipos com maior capacidade de aquisição, absorção, translocação e conversão de $\mathrm{P}$ em matéria seca são de grande interesse. Muitos trabalhos demonstram a variabilidade existente entre espécies e entre cultivares com relação à tolerância à deficiência de $\mathrm{P}$, ao compararem rendimento de matéria seca e de grãos sob condições contrastantes de P. Diferenças entre cultivares de trigo, por exemplo, foram determinadas por diversos autores (Miranda, 1985; Rosa \& Camargo, 1990; Soon, 1992; Abichequer \& Bohnen, 1998), mas, na maioria das vezes, confundem-se com os efeitos da tolerância a elevados teores de $\mathrm{Al}$ nos solos utilizados.

Considerando a escassez das reservas de $\mathrm{P}$, faz-se necessário o desenvolvimento de cultivares mais tolerantes à sua deficiência com o objetivo de minimizar a necessidade de adubação e o custo de produção das lavouras, sem que haja redução no rendimento de grãos (Abichequer \& Bohnen, 1998). O conhecimento nos diferentes genótipos dos mecanismos específicos, envolvidos na aclimatação da planta a condições de baixa disponibilidade de $\mathrm{P}$ no solo, facilitará a seleção de genitores em programas de melhoramento, uma vez que mecanismos diferentes poderão ser combinados, buscando piramidização desses em novos genótipos. O objetivo deste trabalho foi diferenciar genótipos de trigo contrastantes quanto à tolerância à deficiência de $\mathrm{P}$ em hidroponia em curto espaço de tempo.

\section{MATERIAL E MÉTODOS}

Os estudos foram realizados nos Laboratórios de Fisiologia Vegetal e Biologia Molecular Vegetal, do Departamento de Plantas de Lavoura, da Faculdade de Agronomia da Universidade Federal do Rio Grande do Sul, nos anos de 2005 e 2006.

Para atingir o objetivo proposto, foram realizados três estudos com plântulas de trigo em solução hidropônica.

Estudo I - Retirada do endosperma da semente e a resposta à ausência de fósforo em solução nutritiva

Este estudo consistiu da realização de quatro experimentos, nos quais foram testadas a ausência e a baixa disponibilidade de $\mathrm{P}\left(10 \mu \mathrm{mol} \mathrm{L}^{-1}\right)$ sobre algumas características da planta de trigo. Os quatro experimentos seguiram o delineamento experimental de blocos casualizados, com três repetições de 10 plântulas, tendo sido analisados de maneira independente.

A definição das doses de $\mathrm{P}$ a ser utilizada na diferenciação de genótipos deu-se a partir de experimentos piloto e de dados encontrados na literatura, em que se definiu o uso de, além do controle negativo $\left(0 \mu \mathrm{mol} \mathrm{L}{ }^{-1}\right)$, doses de 10 , 30 e $1.000 \mu \mathrm{mol} \mathrm{L}^{-1}$, sendo esta última o controle positivo. Já a dose de $10 \mu \mathrm{mol} \mathrm{L}{ }^{-1}$ aproxima-se das quantidades encontradas em solos naturais (Bissani et al., 2004). A dose de $30 \mu \mathrm{mol} \mathrm{L}-1$ foi definida com base no fato de que espécies silvestres, como a planta-modelo arabidopsis, iniciam respostas de resgate da deficiência de $\mathrm{P}$ apenas em doses menores que $50 \mu \mathrm{mol} \mathrm{L} \mathrm{L}^{-1}$.

O cultivar de trigo utilizado foi o Anahuac, sensível à deficiência de $\mathrm{P}$ em experimentos realizados em solo. Sementes de tamanho similar foram pré-germinadas a $25^{\circ} \mathrm{C}$ e selecionadas as com tamanho similar de radícula, as quais foram distribuídas a uma distância aproximada de $2 \mathrm{~cm}$ sobre telas plásticas adaptadas a tampas de recipientes plásticos de 3,0 L de capacidade, que continham solução nutritiva. A retirada do endosperma da semente foi realizada durante a transferência das plântulas do papel germinador para os recipientes com solução nutritiva. Nos experimentos I e III, o endosperma foi removido e, nos experimentos II e IV, foi mantido (Quadro 1).

Os recipientes com as soluções foram colocados em tanques banho-maria, nos quais a água foi mantida em temperatura de $20^{\circ} \mathrm{C}$, com auxílio de resistências adaptadas ao tanque e de condicionador de ar. As 
Quadro 1. Genótipo, concentrações de fósforo na solução nutritiva, manutenção ou remoção do endosperma e data de coleta e análise dos dados nos experimentos I a IV do Estudo I

\begin{tabular}{ccccc}
\hline Experimento & Genótipo & $\begin{array}{c}\text { Concentração } \\
\text { de P }\end{array}$ & $\begin{array}{c}\text { Manutenção } \\
\text { do endosperma }\end{array}$ & $\begin{array}{c}\text { Tempo de coleta } \\
\text { e análise }\end{array}$ \\
\hline I & Anahuac & 0 e 10 & Não & Cinco dias \\
II & Anahuac & 0 e 10 & Sim & Cinco dias \\
III & Anahuac & 0 e 10 & Não & Dez dias \\
IV & Anahuac & 0 e 10 & Sim & Dez dias \\
\hline
\end{tabular}

condições de luz foram mantidas constantes e os recipientes com a solução foram ligados a um sistema de oxigenação. A solução nutritiva completa foi trocada aos cinco dias de condução de cada experimento, sendo composta por: $\mathrm{Ca}\left(\mathrm{NO}_{3}\right)_{2}$ $4 \mathrm{mmol} \mathrm{L}-1 ; \mathrm{MgSO}_{4}-2 \mathrm{mmol} \mathrm{L}-1 ; \mathrm{KNO}_{3}-4 \mathrm{mmol} \mathrm{L}^{-1}$; $\left(\mathrm{NH}_{4}\right)_{2} \mathrm{SO}_{4}-0,435 \mathrm{mmol} \mathrm{L}-1 ; \mathrm{MnSO}_{4}-2 \mu \mathrm{mol} \mathrm{L}-1$; $\mathrm{CuSO}_{4}-0,3 \mu \mathrm{mol} \mathrm{L}-1 ; \mathrm{ZnSO}_{4}-0,8 \mu \mathrm{mol} \mathrm{L}{ }^{-1} ; \mathrm{NaCl}$ $3 \mu \mathrm{mol} \mathrm{L}-1$; Fe-Geo Fe6 - 0,9 $\mu \mathrm{mol} \mathrm{L}-1 ; \mathrm{Na}_{2} \mathrm{MoO}_{4}$ $0,10 \mu \mathrm{mol} \mathrm{L}-1$ e $\mathrm{H}_{3} \mathrm{BO}_{3}-10 \mu \mathrm{mol} \mathrm{L}{ }^{-1}$. Essa solução foi descrita por Camargo \& Oliveira (1981) e adaptada para trigo por Dornelles (1994).

As variáveis analisadas foram: produção de matéria seca de raízes e parte aérea, razão matéria seca de raízes/parte aérea, teor (concentração) e quantidade de $\mathrm{Pi}$ nas raízes e na parte aérea e eficiências de absorção e translocação de P.

Para determinar a produção de matéria seca de raízes e parte aérea, as 10 plântulas foram seccionadas na ocasião da coleta, lavadas com água destilada, secas em estufa de ventilação forçada a $60^{\circ} \mathrm{C}$ por $48 \mathrm{~h}$ e pesadas. A razão matéria seca de raízes/parte aérea foi obtida pela divisão entre as massas de matéria seca de raízes e parte aérea. Para análise de Pi, aplicou-se o método de Ames (1966) com modificações. A extração de Pi foi realizada em $0,5 \mathrm{ml}$ de TCA $10 \mathrm{cL} \mathrm{L}^{-1}$ (ácido tricloroacético), durante 30 min sob temperatura de $4{ }^{\circ} \mathrm{C}$. Alíquotas do extrato foram retiradas, acrescentando-se a elas uma solução redutora, que continha molibdato de amônio 4,2 $\mathrm{g} \mathrm{L}^{-1}$ em $\mathrm{H}_{2} \mathrm{SO}_{4}$ $0,5 \mathrm{~mol} \mathrm{~L}^{-1}$ e ácido ascórbico $150 \mathrm{~g} \mathrm{~L}^{-1}(6: 1 \mathrm{v} / \mathrm{v})$. Após incubação por $1 \mathrm{~h}$ a $37^{\circ} \mathrm{C}$, avaliou-se a absorbância em espectrofotômetro ultravioleta-visível, modelo Spectronic Gênesis II, em 820 nm, comparando-se com a curva calibrada $\left(0-1 \mu \mathrm{mol} \mathrm{L}-1\right.$ de $\left.\mathrm{KH}_{2} \mathrm{PO}_{4}\right)$. As quantidades de $\mathrm{Pi}$ nas raízes e na parte aérea foram calculadas pela multiplicação do teor de Pi obtido pela massa de matéria seca respectiva de cada parte da plântula. A quantidade total de Pi foi obtida pela soma das quantidades de $\mathrm{P}$ obtidas nas raízes e na parte aérea. A eficiência de absorção de $\mathrm{P}$ foi obtida pela razão entre a quantidade de $\mathrm{Pi}$ total e a massa de matéria seca de raízes. A eficiência de translocação de $\mathrm{P}$ foi obtida pela razão entre as quantidades de Pi na parte aérea e a total na plântula. Nos experimentos I e II, as análises foram realizadas cinco dias após a transferência para a hidroponia e, nos demais, aos 10 dias (Quadro 1).

Estudo II - Diferenciação de genótipos de trigo contrastantes quanto à tolerância à deficiência de fósforo a campo

Foram utilizados dois cultivares que apresentam comportamento contrastante quanto à tolerância à deficiência de $\mathrm{P}$ em condições de solo, Toropi (tolerante) e Anahuac (sensível), três concentrações de P em solução nutritiva $\left(10,30\right.$ e $\left.1.000 \mu \mathrm{mol} \mathrm{L}^{-1} \mathrm{de} P\right)$ e um tratamento-controle (sem aplicação de $\mathrm{P}$ ). A remoção do endosperma da semente foi feita em todos os tratamentos. As condições de crescimento das plântulas foram as mesmas descritas no Estudo I. A coleta das plântulas e as análises foram realizadas 10 dias após a germinação, seguindo o método descrito anteriormente. Foi utilizado o fatorial $2 \times 4$ disposto em delineamento de blocos completamente casualizados, com três repetições.

Estudo III - Uso de hidroponia para identificação de genótipos de trigo contrastantes quanto à tolerância à deficiência de fósforo em linhagens recombinantes

Foi utilizado o em fatorial $7 \times 4$ disposto em delineamento de blocos completamente casualizados, com três repetições, constando os tratamentos de sete genótipos de trigo (dois cultivares e cinco linhagens) e de quatro concentrações de $\mathrm{P}$ em solução nutritiva ( 0 , 10,30 e $1.000 \mu \mathrm{mol} \mathrm{L}^{-1}$ de P). A remoção do endosperma da semente foi feita em todos os tratamentos.

Foram utilizados os cultivares Toropi e Anahuac e cinco linhagens recombinantes $\mathrm{F}_{6}$ obtidas do cruzamento entre Toropi e Anahuac. Esses genótipos foram selecionados com base no seu comportamento sob condições de solo com baixa e alta disponibilidade de P. Dessas linhagens, duas foram selecionadas pela 
similaridade de comportamento sob condições de solo com o cultivar Anahuac (NYW 865-034 e NYW 865073) e três pela similaridade com o cultivar Toropi (NYW 865-016, NYW 865-081 e NYW 865-086). A similaridade dos genótipos diz respeito à razão das características massa de matéria seca da parte aérea na antese e na maturação e massa de matéria seca de raízes na maturação, sob condições de baixa e alta disponibilidade de $\mathrm{P}$ em solo, em casa de vegetação.

As condições de crescimento das plântulas e as determinações realizadas foram as mesmas descritas nos estudos anteriores, à exceção da temperatura do ar, que foi mais elevada (em torno de $26^{\circ} \mathrm{C}$ ) do que nos outros dois estudos. A coleta das plântulas e as análises foram realizadas 10 dias após a germinação, seguindo o método já descrito anteriormente.

Nos três estudos, na análise estatística, utilizouse o programa SAS (Statistical Analysis System), sendo os dados submetidos à análise de variância. A comparação entre médias foi realizada pelo teste de Duncan a $5 \%$.

\section{RESULTADOS E DISCUSSÃO}

O primeiro fator avaliado no trabalho foi o efeito da remoção do endosperma da semente na caracterização de um cultivar de trigo (Anahuac) sensível à deficiência de P (Quadro 2). A presença de P na solução nutritiva aumentou a produção de matéria seca de raízes apenas no experimento em que se retirou o endosperma da semente, na avaliação realizada cinco dias após a germinação. Já a matéria seca da parte aérea não variou com as doses de $\mathrm{P}$ aplicadas em nenhum dos quatro experimentos do Estudo I. Tanto a produção de matéria seca das raízes como a da parte aérea foram ineficientes na discriminação entre as concentrações de P disponibilizadas nas soluções; conseqüentemente, a relação raiz/parte aérea também não foi informativa (dados não apresentados). Considerando os teores de Pi na parte aérea, foi possível diferenciar as doses de P na solução nutritiva apenas no experimento em que a coleta foi realizada 10 dias após a germinação e houve remoção do endosperma nos demais experimentos. Apesar do aumento nominal da concentração de Pi na dose de $10 \mu \mathrm{mol} \mathrm{L}{ }^{-1}$ de $\mathrm{P}$ em relação ao tratamento sem aplicação deste nutriente, essas diferenças não foram significativas.

Considerando que o teor de $\mathrm{P}$ nos tecidos é afetado diretamente pelo crescimento das plântulas, foi calculada a quantidade total de $\mathrm{P}$ nos tecidos com o intuito de verificar a quantidade de $\mathrm{P}$ absorvida da solução nutritiva ou das reservas seminais. As quantidades de P na parte aérea e a total na plântula foram afetadas pelas doses de $\mathrm{P}$ na solução nutritiva somente no experimento em que a coleta das plântulas foi realizada 10 dias após a germinação, com remoção do endosperma da semente (Quadro 2). A quantidade de Pi na parte aérea foi sempre muito superior à quantidade acumulada nas raízes, as quais não diferiram entre si (dados não apresentados) e, em

Quadro 2. Teor e quantidade de fosfato livre (Pi) na parte aérea e total em plântulas do cultivar de trigo Anahuac nos quatro experimentos do Estudo I: aos cinco dias com endosperma, aos cinco dias sem endosperma, aos 10 dias com endosperma e aos 10 dias sem endosperma

\begin{tabular}{|c|c|c|c|c|c|c|c|c|c|c|c|c|}
\hline \multirow{5}{*}{$\begin{array}{c}\text { Característica } \\
\text { avaliada }\end{array}$} & \multicolumn{12}{|c|}{ Época de coleta das plântulas e avaliação (Dias após a emergência) } \\
\hline & \multicolumn{6}{|c|}{5} & \multicolumn{6}{|c|}{10} \\
\hline & \multicolumn{3}{|c|}{ Com endosperma } & \multirow{2}{*}{\multicolumn{3}{|c|}{$\frac{\text { Sem endosperma }}{\text { Dose de } P\left(\mu \mathrm{mol} L^{-1}\right)}$}} & \multicolumn{3}{|c|}{ Com endosperma } & \multicolumn{3}{|c|}{ Sem endosperma } \\
\hline & \multirow[t]{2}{*}{$\mathbf{0}$} & \multirow[t]{2}{*}{10} & \multirow[t]{2}{*}{$\mathbf{C V}$} & & & & \multirow[t]{2}{*}{$\mathbf{0}$} & \multirow[t]{2}{*}{10} & \multirow[t]{2}{*}{$\mathrm{CV}$} & \multirow[t]{2}{*}{$\mathbf{0}$} & \multirow[t]{2}{*}{10} & \multirow[t]{2}{*}{ CV } \\
\hline & & & & $\mathbf{0}$ & 10 & $\mathbf{C V}$ & & & & & & \\
\hline & & & $\%$ & & & $\%$ & & & $\%$ & & & $\%$ \\
\hline $\begin{array}{l}\text { Matéria seca } \\
\text { de raízes }(\mathrm{mg})\end{array}$ & $18^{\mathrm{ns}}$ & 17 & 16 & $3 \mathrm{~B}^{(1)}$ & $7 \mathrm{~A}$ & 20 & $29^{\mathrm{ns}}$ & 26 & 9 & $5^{\mathrm{ns}}$ & 6 & 15 \\
\hline $\begin{array}{l}\text { Matéria seca de } \\
\text { parte aérea }(\mathrm{mg})\end{array}$ & $42^{\mathrm{ns}}$ & 36 & 4,5 & $6^{\mathrm{ns}}$ & 8 & 16 & $71^{\mathrm{ns}}$ & 78 & 12 & $11^{\mathrm{ns}}$ & 15 & 18 \\
\hline $\begin{array}{l}\text { Teor de Pi na parte } \\
\text { aérea }\left(\mathrm{mmol} \mathrm{kg} \mathrm{kg}^{-1}\right)\end{array}$ & $65^{\mathrm{ns}}$ & 139 & 35 & $126^{\mathrm{ns}}$ & 203 & 12 & $87^{\mathrm{ns}}$ & 128 & 41 & $133 \mathrm{~B}$ & $291 \mathrm{~A}$ & 12 \\
\hline $\begin{array}{l}\text { Quantidade de Pi } \\
\text { na parte aérea }(\mu \mathrm{mol})\end{array}$ & $2,7^{\mathrm{ns}}$ & 5 & 38 & $0,8^{\mathrm{ns}}$ & 1,6 & 13 & $6,2 \mathrm{~ns}$ & 9,9 & 31 & $1,4 \mathrm{~B}$ & $4,4 \mathrm{~A}$ & 3 \\
\hline $\begin{array}{l}\text { Quantidade total de } \\
\text { Pi na plântula }(\mu \mathrm{mol})\end{array}$ & $3,2^{\mathrm{ns}}$ & 6,1 & 44 & $0,9^{\mathrm{ns}}$ & 2,4 & 10 & 7,3 ns & 10,5 & 30 & $1,6 \mathrm{~B}$ & $5,3 \mathrm{~A}$ & 6 \\
\hline
\end{tabular}

${ }^{(1)}$ Nas colunas, médias seguidas por mesma letra não diferem entre si na comparação entre doses de $\mathrm{P}$ para o mesmo cultivar pelo teste de Duncan a $5 \%$. ns: não-significativo. 
conseqüência, as quantidades de $\mathrm{P}$ presentes na parte aérea e a total na plântula mostraram comportamentos similares. No experimento com remoção do endosperma e coleta realizada aos 10 dias, houve aumento de mais de $200 \%$ nas quantidades de P na parte aérea e de $\mathrm{P}$, total na plântula no tratamento com $\mathrm{P}$, em relação ao tratamento sem $\mathrm{P}$.

Com remoção do endosperma das plântulas foi possível observar diferenças significativas nas características avaliadas 10 dias após a germinação (Quadro 2). A não-remoção do endosperma da semente faz com que o efeito da deficiência de P não seja observado no estádio de plântula. Isso ocorre porque a semente possui grande quantidade de $\mathrm{P}$ armazenada nas células do endosperma, para utilização da plântula. Segundo Grant et al. (2001), o suprimento externo de $\mathrm{P}$ tem pouco efeito no crescimento de plântulas, mostrando que o período de tempo requerido para a deficiência de $\mathrm{P}$ exercer efeito nos processos de crescimento da plântula depende da quantidade de sua reserva na semente. Dessa forma, a partir dos resultados obtidos no primeiro estudo, definiu-se que a retirada do endosperma é um ponto crucial, para que o efeito de doses de $\mathrm{P}$ possa ser observado no desenvolvimento da plântula de trigo cultivada sob hidroponia.

Em todos os estudos, a matéria seca de raízes e de parte aérea não permitiram diferenciar os genótipos. Houve grande variabilidade entre experimentos e dentro destes, o que fez com que o comportamento dos genótipos não mantivesse um padrão similar nos três estudos (dados não apresentados).

Os cultivares Anahuac e Toropi apresentam comportamento diferente quanto à tolerância à deficiência de $\mathrm{P}$ em condições de solo (Rosa \& Camargo, 1990). O cultivar Toropi é mais tolerante à deficiência de $\mathrm{P}$ que o Anahuac. Ele não responde, em termos de rendimento de matéria seca, à utilização de doses elevadas de $\mathrm{P}$ no solo, enquanto o Anahuac acumula mais matéria seca com maior disponibilidade de $\mathrm{P}$. Esse mesmo comportamento foi observado em hidroponia aos 10 dias após a germinação, não em relação à produção de matéria seca, a qual não diferiu, mas em relação ao teor e à quantidade de Pi na parte aérea e total na plântula.

Os genótipos Toropi e Anahuac diferenciaram-se nas características teor e quantidades de Pi na parte aérea e total na plântula (Quadros 3 e 4) e foi possível também separar as linhagens, selecionadas pela similaridade com esses cultivares em solo, quanto à sua tolerância à deficiência de $\mathrm{P}$ usando essas três características (Quadro 4), indicando que a presença do mecanismo de tolerância pode ser acessada por meio do método usado.

Em relação ao teor de $\mathrm{Pi}$ na parte aérea, foi observada interação entre cultivares e doses de P nos Estudos II e III (Quadros 3 e 4). O cultivar Anahuac aumentou o teor de $\mathrm{P}$ na parte aérea com o incremento da dose de $\mathrm{P}$ na solução nutritiva até a dose de $1.000 \mu \mathrm{mol} \mathrm{L}^{-1}$. Esse mesmo comportamento foi observado nas duas linhagens (NYW 865-034 e NYW 865-073) selecionadas pela similaridade ao cultivar Anahuac. No cultivar Anahuac, no Estudo III, o teor de Pi na parte aérea na dose de $1.000 \mu \mathrm{mol} \mathrm{L}^{-1}$ foi de 96, 147 e $894 \%$ superior aos obtidos nos tratamentos com dose de $\mathrm{P}$ em solução nutritiva de 30 e $10 \mu \mathrm{mol} \mathrm{L}^{-1}$ e sem a presença deste nutriente, respectivamente (Quadro 4). Para os outros genótipos similares ao Anahuac, NYW 865-034 e NYW 865-073, esses valores foram de 124, 88 e $246 \%$ e 82,140 e $1.119 \%$, respectivamente.

Quadro 3. Teor e quantidade de fosfato livre (Pi) na parte aérea e total na plântula dos cultivares de trigo Anahuac e Toropi, considerando as doses de fósforo utilizadas em solução nutritiva aos 10 dias da germinação

\begin{tabular}{|c|c|c|c|c|}
\hline \multirow{2}{*}{ Genótipo } & \multirow{2}{*}{$\begin{array}{l}\text { Dose de P na } \\
\text { solução nutritiva }\end{array}$} & \multirow{2}{*}{$\begin{array}{l}\text { Teor de Pi na } \\
\text { parte aérea }\end{array}$} & \multicolumn{2}{|c|}{ Quantidade de Pi } \\
\hline & & & Parte aérea & Total na plântula \\
\hline \multirow{5}{*}{ Anahuac } & $\mu \mathrm{mol} \mathrm{L} \mathrm{L}^{-1}$ & $\mathrm{mmol} \mathrm{kg}^{-1}$ & $\longrightarrow$ & $\longrightarrow$ \\
\hline & 0 & $35,61 \mathrm{aD}^{(1)}$ & $308,7 \mathrm{aC}$ & $336,3 \mathrm{aC}$ \\
\hline & 10 & $105,07 \mathrm{bC}$ & $1.113,7 \mathrm{aB}$ & $1.209,9 \mathrm{aB}$ \\
\hline & 30 & $152,90 \mathrm{aB}$ & $1.651,3 \mathrm{aB}$ & $1.744,3 \mathrm{aB}$ \\
\hline & 1.000 & $216,38 \mathrm{aA}$ & $2.351,3 \mathrm{aA}$ & $2.530,4 \mathrm{aA}$ \\
\hline \multirow[t]{4}{*}{ Toropi } & 0 & $56,82 \mathrm{aB}$ & $458,3 \mathrm{aB}$ & $504,8 \mathrm{aB}$ \\
\hline & 10 & $151,27 \mathrm{aA}$ & $1.381,6 \mathrm{aA}$ & $1.498,6 \mathrm{aA}$ \\
\hline & 30 & $87,38 \mathrm{bB}$ & $937,9 \mathrm{bAB}$ & $1.024,3 \mathrm{aAB}$ \\
\hline & 1.000 & $143,04 \mathrm{bA}$ & $1.087,1 \mathrm{bA}$ & $1.300,2 \mathrm{bAB}$ \\
\hline $\mathrm{CV}(\%)$ & & 21,3 & 32,6 & 37,4 \\
\hline
\end{tabular}

\footnotetext{
(1) Nas colunas, médias seguidas por mesma letra maiúscula na comparação entre doses para o mesmo cultivar e por uma letra minúscula na comparação entre cultivares dentro da mesma dose de $\mathrm{P}$ não diferem entre si pelo teste de Duncan a $5 \%$.
} 
O cultivar Toropi aumentou o teor de $\mathrm{P}$ livre na parte aérea até a dose de $10 \mu \mathrm{mol} \mathrm{L} \mathrm{L}^{-1}$ de $\mathrm{P}$ na solução nutritiva, não havendo resposta a doses mais elevadas (Quadros 3 e 4). Essa mesma resposta foi observada nas três linhagens selecionadas pela similaridade a esse cultivar (NYW 865-016, NYW 865-081 e NYW 865-086). Houve redução no teor de Pi na parte aérea na dose de $30 \mu \mathrm{mol} \mathrm{L}-1$ de $\mathrm{P}$ na solução nutritiva no cultivar Toropi e na linhagem NYW 865-081, quando comparada à dose de $10 \mu \mathrm{mol} \mathrm{L}^{-1}$. Essas reduções foram de, respectivamente, 18 e $140 \%$ para o cultivar Toropi e a linhagem NYW 865-081 (Quadro 4).

Para as quantidades de Pi na parte aérea e total na plântula, houve interação entre genótipos e doses de P (Quadros 3 e 4). O comportamento das plântulas quanto às características quantidades de Pi na parte aérea e Pi total foi similar. Para essas duas características, o comportamento observado nos genótipos NYW 865-034 e NYW 865-073 foi próximo ao observado no cultivar Anahuac, ou seja, aumentou a quantidade de $\mathrm{P}$ com o incremento da dose de $\mathrm{P}$ utilizada na solução nutritiva até a dose de $1.000 \mu \mathrm{mol} \mathrm{L}{ }^{-1}$. Apesar de Anahuac ter mantido o mesmo comportamento nos Estudos II e III, observou-se que as quantidades de $\mathrm{P}$ acumuladas no Estudo III foram sempre menores que as do estudo II (Quadros 3 e 4). E possível que a temperatura ambiente mais elevada durante o Estudo III tenha afetado a absorção.

O menor acúmulo de $\mathrm{P}$ na parte aérea das plântulas no Estudo III em relação às do Estudo II não permitiu observar diferença $(\mathrm{P}>0,05)$ entre as doses de $\mathrm{P}$ no cultivar Toropi (Quadro 4). Esse mesmo comportamento foi observado na linhagem NYW 865-086, similar ao Toropi quanto à tolerância à deficiência de $\mathrm{P}$ no solo. Os outros dois genótipos similares ao Toropi aumentaram a quantidade de Pi na parte aérea somente até a dose de $10 \mu \mathrm{mol} \mathrm{L}{ }^{-1}$ de $\mathrm{P}$ na solução nutritiva, não havendo resposta a doses mais elevadas. Houve tendência de redução nas quantidades de Pi na parte aérea e total na plântula na dose de $30 \mu \mathrm{mol} \mathrm{L}{ }^{-1}$ de P na solução nutritiva no cultivar Toropi e na linhagem NYW 865-081 (Quadro 4).

Comparando as doses de 10 e $1.000 \mu \mathrm{mol} \mathrm{L}^{-1}$, observaram-se aumentos de mais de $100 \%$ no teor e na quantidade de Pi na parte aérea das plântulas de Anahuac nos estudos realizados. Dessa forma, dividindo os valores encontrados na menor dose pelos valores da dose maior, obtém-se razão menor que 0,5 . Já o cultivar Toropi apresenta teores de Pi na parte aérea e total na plântula similares nas doses de 10 e $1.000 \mu \mathrm{mol} \mathrm{L}^{-1}$ (Quadros 3 e 4), indicando que, na dose de $10 \mu \mathrm{mol} \mathrm{L}^{-1}$ de $\mathrm{P}$, a plântula já consegue manter seu metabolismo funcionando plenamente.

Os dados obtidos evidenciam que as diferenças na tolerância à deficiência de $\mathrm{P}$ entre genótipos podem estar relacionadas com maior habilidade de regular o transporte de $\mathrm{P}$ das raízes para a parte aérea. $\mathrm{O}$ cultivar Toropi é capaz de manter constantes os teores de Pi na parte aérea, apresentando concentração de $\mathrm{Pi}$ superior à do Anahuac na dose de $10 \mu \mathrm{mol} \mathrm{L}^{-1}$ e inferior nas doses de 30 e $1.000 \mu \mathrm{mol} \mathrm{L}^{-1}$ (Quadros 3 e 4). As diferentes concentrações de Pi na parte aérea nos dois cultivares podem não ser conseqüência não só da habilidade de translocação da planta, mas também da capacidade de absorção e, principalmente, da eficiência de uso de $\mathrm{P}$.

Rosa \& Camargo (1990) verificaram que Toropi aumenta significativamente a massa de raízes em resposta à limitação de $\mathrm{P}$, sugerindo que a tolerância se deva à maior capacidade de extração de $\mathrm{P}$ do solo. Nesse trabalho, no entanto, dado o curto período de crescimento, não foram observadas diferenças na massa (Quadro 2) ou no comprimento (dados não apresentados) das suas raízes. Além disso, a maior capacidade de absorção de $\mathrm{P}$ do meio não pôde ser avaliada, dada a dificuldade de se analisar o efeito da secreção de quelantes e de enzimas em solução nutritiva. Assim, o método empregado na presente pesquisa diferencia os indivíduos com base nas eficiências de absorção e, ou, de uso de P. É possível inferir que Toropi apresente pelo menos dois mecanismos distintos que conduzem à tolerância à deficiência de $\mathrm{P}$ em solos: um relacionado com o aumento da superfície de absorção das raízes, confirmado pelo significativo aumento na relação raizl parte aérea (Rosa \& Camargo, 1990), e o mecanismo que operou durante a realização do presente trabalho, possivelmente, maior eficiência de uso e, ou, transporte de $\mathrm{P}$.

A limitação de $\mathrm{P}$ é percebida por dois tipos de sensores, um local, no sistema radicular, avaliando o meio externo (Delatorre et al., 2004), e outro "sistêmico", avaliando o status de P da planta como um todo (Abel et al., 2000). O sensor sistêmico possivelmente avalia a manutenção dos teores mínimos de Pi no citossol ou no cloroplasto e define o transporte de $\mathrm{P}$ para a parte aérea, além de induzir mecanismos de resgate da limitação. Se a planta for eficiente no uso de $\mathrm{P}$, possivelmente os teores de Pi são mantidos, apesar do menor aporte de $\mathrm{P}$ do solo. Sabe-se que o transporte para a parte aérea é regulado, como comprovam os mutantes de arabidopsis Pho2 (Dong et al., 1998) e At4 (Shin et al., 2006), ambos acumulando $\mathrm{Pi}$ em excesso na parte aérea e sendo incapazes de tolerar limitação de $\mathrm{P}$ no solo. Esses defeitos devem alterar a percepção e a regulação do teor de P na parte aérea (Hamburguer et al., 2002; Dong et al., 1998). Sugere-se que Pho2 seja membro da cadeia de transdução dos teores de P na parte aérea envolvida na regulação do transporte de $\mathrm{P}$ das raízes à parte aérea. Proteínas com essa função e expressas de forma diferencial ou com características cinéticas diferentes podem estar envolvidas no comportamento diferencial observado entre as cultivares Toropi e Anahuac. 
Quadro 4. Teor e quantidade de fosfato livre (Pi) na parte aérea e total das plântulas de genótipos de trigo, considerando as doses de fósforo utilizadas em solução nutritiva aos 10 dias da germinação

\begin{tabular}{|c|c|c|c|c|}
\hline \multirow{2}{*}{ Genótipo } & \multirow{2}{*}{$\begin{array}{c}\text { Dose de P na } \\
\text { solução nutritiva }\end{array}$} & \multirow{2}{*}{$\begin{array}{l}\text { Teor de Pi na } \\
\text { parte aérea }\end{array}$} & \multicolumn{2}{|c|}{ Quantidade de Pi } \\
\hline & & & Parte aérea & Total na plântula \\
\hline & $\mu \mathrm{mol} \mathrm{L}^{-1}$ & $\mathrm{mmol} \mathrm{kg}{ }^{-1}$ & 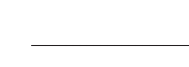 & $1 \longrightarrow$ \\
\hline Anahuac & $\begin{array}{r}0 \\
10 \\
30 \\
1.000\end{array}$ & $\begin{array}{r}9,7 \mathrm{~B} \\
57,3 \mathrm{~B} \\
73,3 \mathrm{~B} \\
152,1 \mathrm{~A}\end{array}$ & $\begin{array}{r}55,9 \mathrm{~B} \\
279,6 \mathrm{~B} \\
354,1 \mathrm{~B} \\
781,5 \mathrm{~A}\end{array}$ & $\begin{array}{l}73,1 \mathrm{~B} \\
306,1 \mathrm{~B} \\
499,5 \mathrm{AB} \\
919,1 \mathrm{~A}\end{array}$ \\
\hline NYW 865-034 & $\begin{array}{r}0 \\
10 \\
30 \\
1.000\end{array}$ & $\begin{array}{r}35,7 \mathrm{~B} \\
61,7 \mathrm{~B} \\
51,1 \mathrm{~B} \\
123,8 \mathrm{~A}\end{array}$ & $\begin{array}{l}131,0 \mathrm{~B} \\
271,3 \mathrm{~B} \\
212,7 \mathrm{~B} \\
521,5 \mathrm{~A}\end{array}$ & $\begin{array}{l}163,4 \mathrm{C} \\
340,0 \mathrm{~B} \\
249,5 \mathrm{BC} \\
609,0 \mathrm{~A}\end{array}$ \\
\hline NYW 865-073 & $\begin{array}{r}0 \\
10 \\
30 \\
1.000\end{array}$ & $\begin{array}{r}22,1 \mathrm{C} \\
102,7 \mathrm{~B} \\
131,8 \mathrm{~B} \\
247,4 \mathrm{~A}\end{array}$ & $\begin{array}{r}111,8 \mathrm{C} \\
580,5 \mathrm{~B} \\
806,2 \mathrm{~B} \\
1.533,8 \mathrm{~A}\end{array}$ & $\begin{array}{r}134,0 \mathrm{C} \\
607,1 \mathrm{~B} \\
886,7 \mathrm{~B} \\
1.723,6 \mathrm{~A}\end{array}$ \\
\hline Toropi & $\begin{array}{r}0 \\
10 \\
30 \\
1.000\end{array}$ & $\begin{array}{l}45,9 \mathrm{~B}^{(1)} \\
84,8 \mathrm{AB} \\
71,7 \mathrm{AB} \\
126,8 \mathrm{~A}\end{array}$ & $\begin{array}{l}256,5^{\mathrm{ns}} \\
537,3 \\
406,4 \\
552,0\end{array}$ & $\begin{array}{l}283,4 \mathrm{~B} \\
573,1 \mathrm{~A} \\
500,4 \mathrm{AB} \\
653,0 \mathrm{~A}\end{array}$ \\
\hline NYW 865-016 & $\begin{array}{r}0 \\
10 \\
30 \\
1.000\end{array}$ & $\begin{array}{l}20,8 \mathrm{~B} \\
61,0 \mathrm{AB} \\
88,7 \mathrm{~A} \\
95,2 \mathrm{AB}\end{array}$ & $\begin{array}{l}119,1 \mathrm{~B} \\
342,0 \mathrm{AB} \\
430,7 \mathrm{AB} \\
610,8 \mathrm{~A}\end{array}$ & $\begin{array}{l}153,2 \mathrm{~B} \\
423,5 \mathrm{AB} \\
567,5 \mathrm{~A} \\
812,3 \mathrm{~A}\end{array}$ \\
\hline NYW 865-081 & $\begin{array}{r}0 \\
10 \\
30 \\
1.000\end{array}$ & $\begin{array}{r}29,6 \mathrm{~B} \\
108,7 \mathrm{~A} \\
55,0 \mathrm{~B} \\
165,2 \mathrm{~A}\end{array}$ & $\begin{array}{l}132,4 \mathrm{~B} \\
531,2 \mathrm{~A} \\
347,6 \mathrm{AB} \\
772,9 \mathrm{~A}\end{array}$ & $\begin{array}{l}143,0 \mathrm{~B} \\
597,0 \mathrm{~A} \\
409,0 \mathrm{AB} \\
819,0 \mathrm{~A}\end{array}$ \\
\hline NYW 865-086 & $\begin{array}{r}0 \\
10 \\
30 \\
1.000\end{array}$ & $\begin{array}{l}44,1 \mathrm{~B} \\
70,4 \mathrm{AB} \\
71,5 \mathrm{AB} \\
93,0 \mathrm{~A}\end{array}$ & $\begin{array}{l}244,5 \mathrm{~ns} \\
470,0 \\
446,6 \\
437,3\end{array}$ & $\begin{array}{l}263,1 \mathrm{~B} \\
544,6 \mathrm{AB} \\
502,1 \mathrm{~A} \\
545,8 \mathrm{AB}\end{array}$ \\
\hline CV (\%) & & 42,5 & 57,9 & 37,3 \\
\hline
\end{tabular}

(1) Nas colunas, médias seguidas por mesma letra não diferem entre si na comparação entre doses de $\mathrm{P}$ para o mesmo cultivar pelo teste de Duncan a $5 \%$. ns: não-significativo.

A maior tolerância de um genótipo está relacionada com o melhor controle de transporte de P para a parte aérea, e a maior eficiência de utilização na parte aérea faz sentido quando se considera que é nela que ocorre a fotossíntese e a definição de alocação de carboidratos que mantém o crescimento da plântula. Quando existe limitação e exaustão do $\mathrm{P}$ acumulado nos vacúolos, as plântulas passam a manter praticamente todo o P no citoplasma e nos cloroplastos (Marschner, 1995). A regulação no transporte de $\mathrm{P}$ para a parte aérea condiciona o suprimento desse nutriente aos locais fotossinteticamente ativos da plântula, mantendo o crescimento e o desenvolvimento adequados.

A maior eficiência de transporte de $\mathrm{P}$ das raízes para a parte aérea pode estar relacionada com a quantidade e o tipo de transportadores de fosfato presentes em cada cultivar nos tecidos que dão acesso ao transporte de longa distância. Existem dois sistemas de transporte de P nas células: o de baixa e o de alta afinidade (Bieleski, 1973). O sistema de baixa afinidade parece ser expresso de maneira constitutiva, enquan- to o de alta afinidade tem membros induzidos em condições de baixa disponibilidade de $\mathrm{P}$ no sistema (Raghothama, 1999; Daram et al., 1999). Assim, podese hipotetizar que o cultivar Toropi disponha de maior capacidade de regulação desses sistemas, principalmente o de alta afinidade, fazendo com que, mesmo numa condição de baixa disponibilidade de $\mathrm{P}$, transporte e absorva mais $\mathrm{P}$ e, por conseqüência, apresente rendimento similar ao obtido sob alta disponibilidade desse nutriente. Seguindo essa hipótese, os genótipos mais tolerantes à deficiência de $\mathrm{P}$ (NYW 865016, NYW 865-081, NYW 865-086 e Toropi) levariam à expressão de genes que codificam transportadores de alta afinidade de $\mathrm{P}$ e, dessa forma, teriam maior capacidade para transportar esse nutriente. Isso também poderia explicar o fato de o cultivar Toropi apresentar maior teor de Pi na parte aérea que o Anahuac nas doses mais baixas de P (Quadros 3 e 4).

$\mathrm{O}$ comportamento de linhagens recombinantes $\mathrm{F}_{6}$ oriundas do cruzamento Toropi x Anahuac foi avaliado, usando a metodologia do Estudo II, como forma de 
testar a repetibilidade da análise, uma vez que as linhagens recombinantes utilizadas foram selecionadas por contrastarem em relação à tolerância à limitação de $\mathrm{P}$, como os genitores, mas são mais similares entre si para outras características. As linhagens NYW 865-034 e NYW 865-073 apresentaram resultados similares aos obtidos no cultivar Anahuac, e as linhagens NYW 865-016, NYW 865-081 e NYW 865-086 foram similares ao Toropi (Quadro 4), corroborando os dados obtidos sob condições de solo por Minella ${ }^{(7)}$ em relação à matéria seca (comunicação pessoal).

Dessa forma, os resultados dos três estudos evidenciam que o fator que determina maior tolerância à deficiência de $\mathrm{P}$ no cultivar Toropi está relacionado com maior eficiência de uso de P. Ele também engloba o transporte de $\mathrm{P}$ das raízes para a parte aérea por meio de transportadores de $\mathrm{P}$ envolvidos no carregamento desse nutriente para o xilema, para que seja levado à parte aérea, bem como no carregamento posterior nas células da parte aérea. Hamburguer et al. (2002) identificaram em Arabidopsis thaliana, em estudo de mutantes, um gene denominado $\mathrm{PHO1}$, que codifica justamente uma proteína de carregamento de $\mathrm{P}$ para o xilema. Tal gene pertence a uma família gênica, havendo pelo menos um outro membro, $\mathrm{PHO1}$; H1, com função similar (Stefanovic et al., 2007).

Em resumo, usando o método e avaliando o teor ou a quantidade de Pi na parte aérea e total da plântula nas doses de 10 e $1.000 \mu \mathrm{mol} \mathrm{L} \mathrm{L}^{-1}$, foi possível diferenciar, em solução, os genótipos considerados contrastantes quanto à tolerância à deficiência de $\mathrm{P}$ sob condições de solo. Entre essas duas doses, os cultivares mais tolerantes não apresentaram diferença significativa (razão próxima a 1,0) enquanto as sensíveis à deficiência de $\mathrm{P}$ aumentariam os valores de teor e quantidade de Pi na parte aérea e a total na plântula até a maior dose (razão próxima a 0,5).

\section{CONCLUSÕES}

1. O endosperma da semente de trigo dispõe de reservas de $\mathrm{P}$ que impedem a observação de diferenças morfofisiológicas em resposta à sua limitação no ambiente no estádio de plântula.

2. Com a remoção do endosperma da semente, é possível diferenciar genótipos de trigo quanto à tolerância à deficiência de $\mathrm{P}$ em solução hidropônica, 10 dias após a germinação, se o mecanismo de tolerância não envolver a habilidade de extração de $\mathrm{P}$ ou a associação a micorrizas.

\footnotetext{
(7) Euclydes Minella, pesquisador do Centro Nacional de Pesquisa do Trigo (EMCAPA).
}

3. A diferenciação pode ser feita por meio do cálculo da razão entre os valores de teor de Pi na parte aérea obtidos nas doses de 10 e $1.000 \mu \mathrm{mol} \mathrm{L}^{-1}$ de $\mathrm{P}$, ficando, nos genótipos tolerantes, essa razão próxima a 1,0 e, nos genótipos sensíveis, próxima a 0,5 .

4. As características quantidade de Pi na parte aérea ou total na plântula são tão informativas quanto o teor de Pi na parte aérea.

5. O cultivar Toropi e as linhagens selecionadas pela similaridade no seu comportamento em condições de solo (NYW 865-016, NYW 865-081 e NYW 865-086) são mais tolerantes à deficiência de $\mathrm{P}$ em solução, quando comparados o cultivar Anahuac e as linhagens NYW 865-034 e NYW 865-073.

\section{AGRADECIMENTOS}

Ao Dr. Euclides Minella (Embrapa - Trigo), por ceder as linhagens recombinantes. Ao CNPq, pelas bolsas de pós-graduação e de iniciação científica dos estudantes participantes. À FAPERGS, pelo apoio financeiro ao projeto e pela bolsa de iniciação científica.

\section{LITERATURA CITADA}

ABEL, S.; NÜRNBERGER, T.; AHNERT, V.; KRAUSS, G.J. \& GLUND, K. Induction of an extracellular cyclic nucleotide phosphodiesterase as an accessory ribonucleolytic activity during phosphate starvation of cultured tomato cells. Plant Physiol., 122:543-552, 2000.

ABICHEQUER, A.D. \& BOHNEN, H. Eficiência de absorção, translocação e utilização de fósforo por variedades de trigo. R. Bras. Ci. Solo, 22:21-26, 1998.

AMES, B.N. Assay of inorganic phosphate, total ortophosphate and phosphatases. In: NEUFELD, E. \& GINSBURG, V. Methods in enzymology. San Diego, Elsevier Academic Press, 1966. v.8. p.115-118.

BIELESKI, R.L. Phosphate pools, phosphate transport, and phosphate availability. Ann. Rev. Plant Physiol., 24:225$252,1973$.

BISSANI, C.A.; GIANELLO, C.; TEDESCO, J.M. \& CAMARGO, F.O.C. Fertilidade dos solos e manejo da adubação de culturas. Porto Alegre, Gênesis, 2004. 328p.

CAMARGO C.E.O. \& OLIVEIRA, O.F. Tolerância de cultivares de trigo a diferentes níveis de alumínio em solução nutritiva e no solo. Bragantia, 40:21-31, 1981.

DARAM, P.; BRUNNER, S.; RAUSCH. C.; STEINER. C.; AMRHEIN, N. \& BUCHER, M. Pht2; 1 encodes a lowaffinity phosphate transporter from Arabidopsis. Plant Cell, 11:2153-2166, 1999. 
DELATORRE, C.A.; TICCONI, C.A.; LAHNER, B.; SALT, D.E. $\&$ ABEL, S. Arabidopsis pdr2 reveals a phosphate-sensitive checkpoint in root development. Plant J., 37:801-814, 2004.

DONG, B.; RENGEL, Z. \& DELHAIZE, E. Uptake and translocation of phosphate by pho2 mutant and wild-type seedlings of Arabidopsis thaliana. Planta, 205:251-256, 1998.

DORNELLES, A.L.C. O uso da cultura de tecidos na geração de variabilidade para tolerância à toxicidade do alumínio e sensibilidade ao ácido giberélico em trigo (Triticum aestivum L.). Porto Alegre, Universidade Federal do Rio Grande do Sul, 1994. 102p. (Tese de Doutorado)

FERNANDES, C. Eficiência de diferentes cultivares de híbridos de milho quanto a utilização de fósforo em solos de Cerrado. Piracicaba, Escola Superior de Agricultura "Luiz de Queiroz", 2001. 51p. (Tese de Mestrado)

GERLOFF, G.C. \& GABELMAN, W.H. Genetic basis of inorganic plant nutrition. In: LÄUCHLI, A. \& BIELESKI, R.L., eds. Inorganic plant nutrition. New York, SpringerVerlag, 1983. p.453-480.

GODDARD, R.E. \& HOLLIS, C.A. The genetic basis of florest tree nutrition. In: NAMBIAR, E.K.S., ed. Nutrition of plantation forests. London, Academic Press, 1984. p.237258 .

GOEDERT, W.J. Nutrient use efficiency in Brazilian acid soils: Nutrient management and plant efficiency. In: MONIZ, A.C., ed. Plant soil interactions at low pH: Sustainable agriculture and forest production. In: INTERNATIONAL SYMPOSIUM ON PLANT-SOIL INTERACTIONS AT LOW PH, 4., Belo Horizonte, 1998. Proceedings. Belo Horizonte, 1998. p.29-38.

GONÇALVES, J.L.M.; FIRME, D.J.; NOVAIS, R.F. \& RIBEIRO, A.C. Cinética de adsorção de fósforo em solos de cerrado. R. Bras. Ci. Solo, 9:107-111, 1997.

GRANT, C.A.; PLATEN, D.N.; TOMAZIEWICZ, D.J. \& SHEPPARD, S.C. A importância do fósforo no desenvolvimento inicial da planta. Inf. Agron., 1:1-5, 2001.

HAMBURGUER, D.; REZZONICO, E.; MACDONALDCOMBER PETE'TOT, J.; SOMERVILLE, C. \& POIRIER, Y. Identification and characterization of the arabidopsis PHO1 gene involved in phosphate loading to the xylem. Plant Cell, 14:889-902, 2002.
LEAL, J.R. \& VELLOSO, A.C.X. Adsorção de fósforo em Latossolos sob vegetação de cerrado. Pesq. Agropec. Bras., 8:81-88, 1973 .

MARSCHNER, H. Functional of mineral nutrients: Macronutrients. In: Mineral nutrition of higher plants. London, Academic Press, 1995. 330p.

MIRANDA, L.N. Aluminum-phosphate interactions in relation to wheat growth. Reading, University of Reading, 1985. 169p. (Tese de Doutorado)

NOVAIS, R.F. \& BARROS, N.F. Sustainable agriculture and forestry production systems on acid silts: Phosphorus as a case-study. In: MONIZ, A.C., ed. Plant soil interactions at low $\mathrm{pH}$ : Sustainable agriculture and forest production. In: INTERNATIONAL SYMPOSIUM ON PLANT SOIL INTERACTIONS AT LOW PH, 4., Belo Horizonte, 1997. Proceedings. Belo Horizonte, 1997. p.29-38.

RAGHOTHAMA, K.G. Phosphate acquisition. Ann. Rev. Plant Physiol. Plant Molec. Biol., 50:665-693, 1999.

ROSA, O.S. \& CAMARGO, C.E.O. Wheat breeding for better efficiency in phosphorus use. In: SAUNDERS, D.A., ed. Wheat for the nontraditional warm areas: A proceeding of the international conference. Foz do Iguaçu, United Nations Development Programme International Maize and Wheat Improvement Center, 1990. p.333-351.

SANCHEZ, P.A. \& SALINAS, J.G. Low input technology for managing Oxisols and Ultisols in Tropical America. Adv. Agron., 34:279-398, 1981.

SHIN, H.; SHIN, H.S.; CHEN, R. \& HARRISON, M.J. Loss of At4 function impacts phosphate distribution between the roots and the shoots during phosphate starvation. Plant J., 5:712-726, 2006.

SOON, Y.K. Differential response of wheat genotypes to phosphorus in acid soils. J. Plant Nutr., 15:513-526, 1992.

STEFANOVIC, A.; RIBOT, C.; ROUACHED, H.; WANG, Y.; CHONG, J.; BELBAHRI, L.; DELESSERT, S. \& POIRIER, Y. Members of the PHO1 gene family show limited functional redundancy in phosphate transfer to the shoot, and are regulated by phosphate deficiency via distinct pathways. Plant J., 50:982-994, 2007. 